\title{
COMPORTAMENTO DO CONSUMIDOR VERSUS ESTRATÉGIAS DE OPERAÇÕES A PONTE CLIENTE-EMPRESA
}

$\star$ José Paulo Alves Fusco

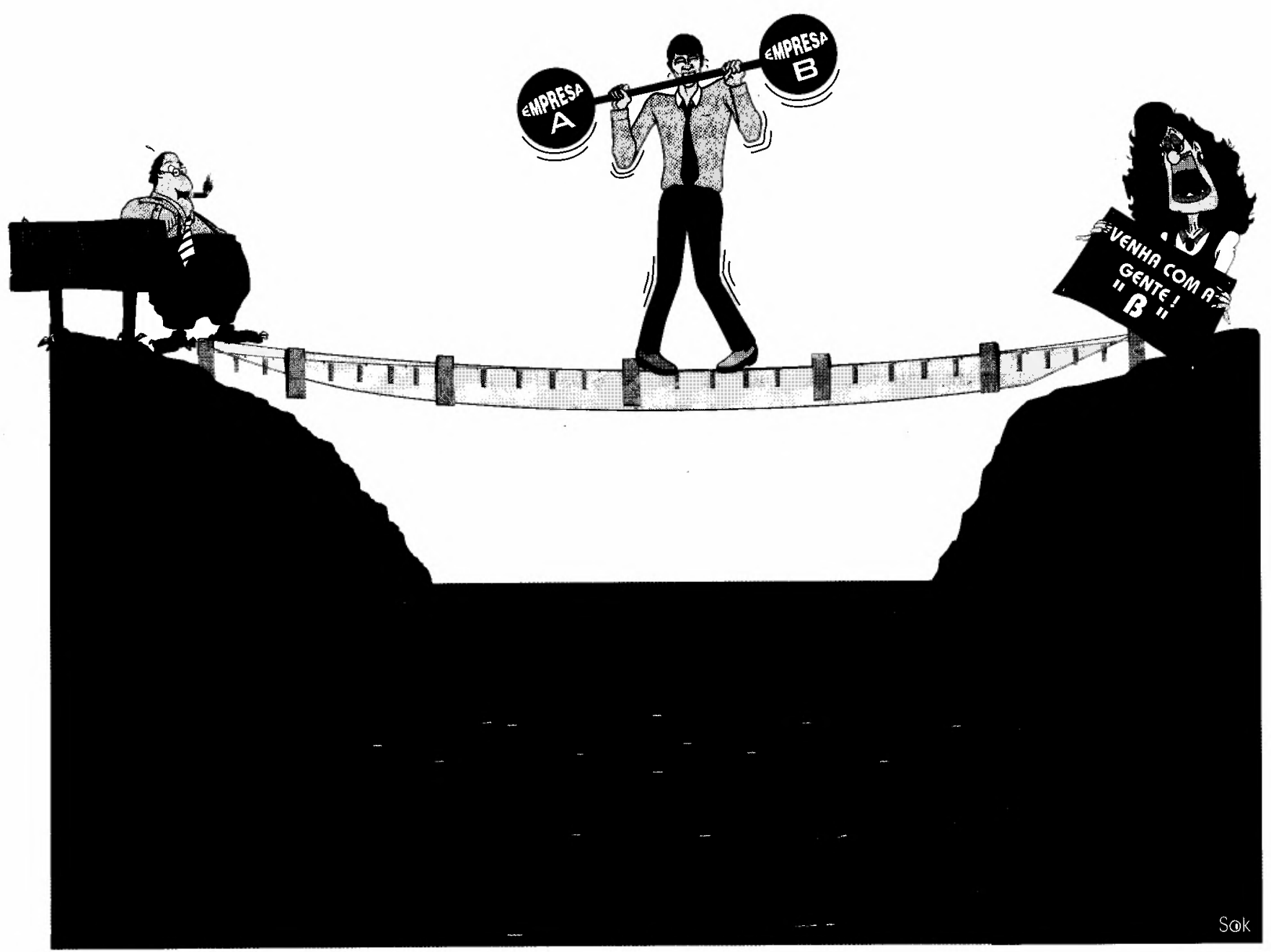

PALAVRAS-CHAVE:

comportamento do consumidor, estratégia de manufatura, estratégia de operações, clientes, competitividade.

KEY WORDS:

consumer behavior, manufacturing strategy, operations strategy, clients, competitiveness.

$\star$ Engenheiro, Mestre e Doutorando pela Escola Politécnica da USP, Consultor de Empresas.

42 Revista de Administração de Empresas

São Paulo, v. 35, n. 4, p. 42-51 


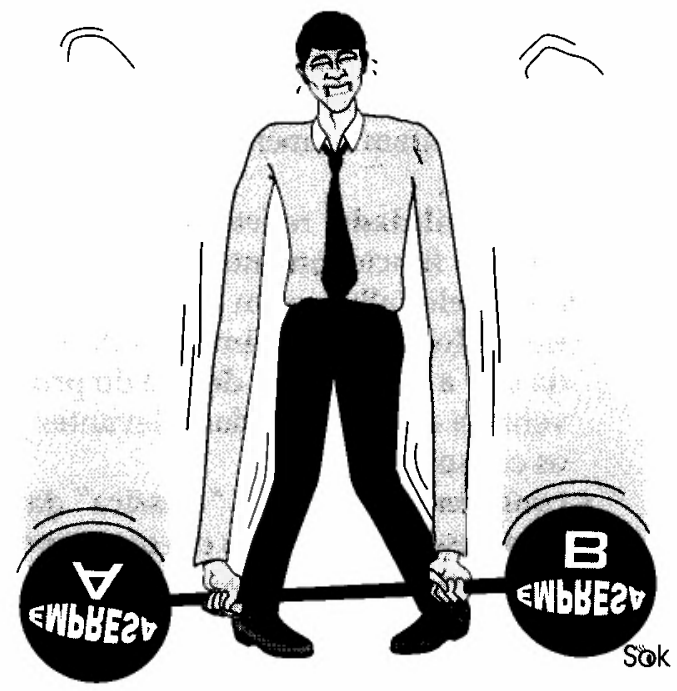

Análise das relações que existem entre o comportamento do consumidor e a elaboração de estratégias de operações de uma empresa.

\section{Analysis of relationship between consumer behavior and the development of operation strategies in a company.}

O presente trabalho tem por objetivo examinar e discutir aspectos correspondentes ao comportamento do consumidor e estratégias de operações. São tecidas, ainda, algumas considerações sobre como traduzir e interpretar os impulsos que recebem os sistemas de manufatura - os quais têm sua origem nas forças de mercado - , de modo a se obterem elementos que permitam a formação de estratégias de operações mais pertinentes à realidade dos consumidores.

Inicialmente, apresentam-se um breve resumo e comentários sobre a abordagem de Garvin ${ }^{1}$ com relação à qualidade do produto, propondo oito dimensões estruturadas que permitem um contexto analítico coerente para estudar e definir o perfil do produto sob o ponto de vista do consumidor.

Apresenta-se também a tipologia proposta por Engel, Blackwell e Miniard ${ }^{2}$ acerca das dimensões de necessidades dos consumidores, as quais definem um mix, que é função do segmento de mercado, das situações de uso, do nível de renda do grupo e estilo próprio de vida, cujas características devem ser atendidas para se ter alguma chance de sucesso no negócio.

Em seguida, examinam-se alguns pontos referentes aos fatores "qualificadores" $\mathrm{e}$ "ganhadores de pedidos" colocados por Hill $^{3}$, bem como sua pertinência em relação às análises de consciência e de imagem propostas por Engel, Blackwell e Miniard ${ }^{4}$.

Ainda nessa linha de pensamento, o trabalho traz um paralelo entre as dimensões de necessidades e as dimensões competi- tivas propostas por Slack e Corrêa e Gianesi ${ }^{5}$, voltadas a operações de manufatura e serviços.

Fazendo um "fecho" do assunto, o trabalho examina conjuntamente as propostas de todos esses pesquisadores, fazendo então resultar algumas conclusões e aspectos considerados de interesse, que podem representar importantes oportunidades futuras para pesquisas.

\section{AS MÚLTIPLAS DIMENSÕES DA QUALIDADE}

De maneira mais ampla e sistêmica do que seus antecessores, Garvin ${ }^{6}$ procura oferecer uma abordagem estratégica da Qualidade, que resulte em um contexto mais intimamente ligado à lucratividade e aos objetivos empresariais básicos, mais sensível às necessidades da concorrência e ao ponto de vista do consumidor, além de mais firmemente associada à melhoria contínua.

A análise da competição entre produtos concorrentes torna-se muito mais comple$x a$, uma vez que dimensões múltiplas implicam que os produtos podem ser diferentes e concorrer entre si de inúmeras maneiras. Desse modo, uma empresa que opte por competir em Qualidade pode fazê-lo de diversas formas, sem precisar buscar a excelência em todas as oito dimensões ao mesmo tempo.

Tendo identificado as dimensões críticas da Qualidade num mercado, as empresas podem, então, relacioná-las a atributos específicos dos produtos (através de técnicas do tipo QFD - Quality Function
1. GARVIN, D.A. Gerenciando a qualidade: a visão estratégica e competitiva. Rio de Janeiro: Qualitymark, 1992.

2. ENGEL, J.F., BLACKWELL, R.D., MINIARD, P.W. Consumer behavior. 7 ed., Fort Worth: The Dryden Press, 1993, p. 266-97.

3. HILL, T. Manufacturing strategy: text and cases. New York: Irwin, 1989.

4. ENGEL, J. F., BLACKWELL, R.D., MINIARD, P.W. Op. cit.

5. SLACK, N. Vantagemcompetitiva em manufatura. São PauIo: Atlas, 1993; GIANESI, I.G.N. CORRÊA, H. L. Contributions to service operations strategy development. In: Service Superiority - the design and delivery of effective service operations. Warwick: R. Johnston and N.D.C. Slack eds. 1993, p. 13-9.

6. GARVIN, D. A. Op. cit. 
Deployment) e priorizar as açōes necessárias ao seu pleno atendimento.

As implicaçōes administrativas e estratégicas desse tipo de análise devem estar claras. Após escolher as dimensóes de Qualidade em que espera competir, uma empresa pode lucrar ajustando a organização e suas operações para atender a essas necessidades específicas. Caso contrário, pode dar mais força aos departamentos errados ou ainda fazer coisas erradas ou com impacto marginal na percepção de necessidades dos consumidores.

No entanto, ainda deve ser examinada a questão acerca dos processos utilizados internamente pelo consumidor, para se atribuir pesos maiores ou menores a cada uma dessas dimensōes.

Garvin $^{7}$ apresenta e conceitua adicionalmente oito dimensōes (ou categorias) da Qualidade, de modo a obter uma visão estruturada e sistêmica que permita maior poder de análise objetiva, além de subsidiar ações competitivas concretas no âmbito do sistema de operações das empresas (ver figura 1).

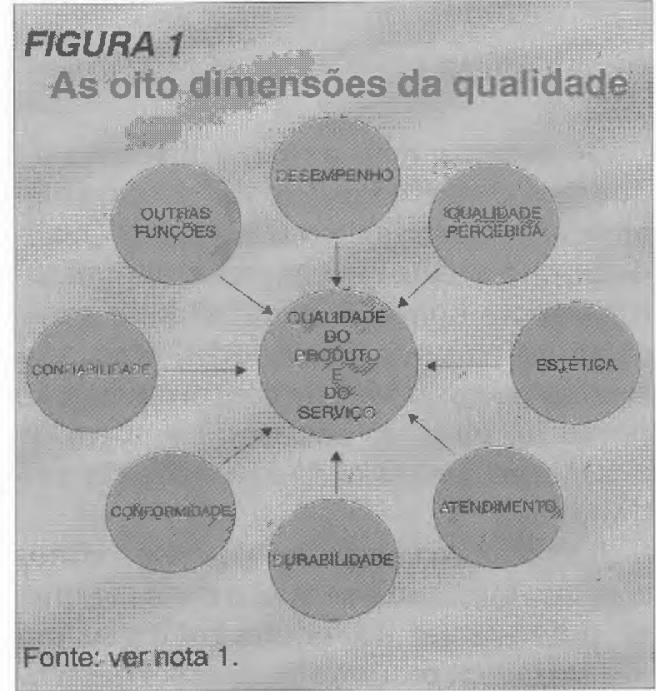

7. Idem, ibidem.

8. Idem, ibidem.
- outras funções: corresponde aos "adereços" dos produtos, ou seja, aquelas características ou funçōes secundárias que suplementam o funcionamento básico do produto;

- confiabilidade: reflete a probabilidade de mau funcionamento de um produto, ou de ele falhar num determinado período. Torna-se mais importante à medida que a interrupção de uso do produto venha a acarretar perdas relevantes para os consumidores;

- conformidade: a mais "clássica" das dimensões, reflete o grau em que o projeto e as características operacionais de um produto estão de acordo com padrōes preestabelecidos. Nas empresas de manufatura, podemos citar a "freqüência de reparos em garantia" como uma medida de conformidade;

- durabilidade: sendo uma medida de vida útil do produto, Garvin ${ }^{8}$ coloca duas dimensões, econômica e técnica, para defini-la. Tecnicamente, pode-se definir durabilidade como o uso proporcionado por um produto, até este se deteriorar fisicamente. Economicamente, pode-se defini-la como sendo o uso que se consegue de um produto antes de sua quebra, sendo a sua substituição considerada preferível aos constantes reparos;

- atendimento (serviceability): muito importante, particularmente para empresas prestadoras de serviços, ao atendimento corresponde a rapidez, cortesia e facilidade de reparo. Os consumidores não se preocupam apenas com a possibilidade de um produto estragar, mas também com o tempo que são obrigados a esperar até o restabelecimento das condiçōes normais, com a pontualidade do atendimento às suas chamadas, seu relacionamento com o pessoal de atendimento a freqüência com que as chamadas para serviços ou reparos deixam de resolver os problemas. Pesquisas feitas demonstram a íntima correlação do grau de satisfação com o atendimento e a disposição dos consumidores de comprar mais uma vez as marcas que lhes tenham causado problemas;

- estética: a estética - a aparência de um produto, o que se sente com ele, qual o seu som, sabor ou cheiro - é, sem dúvida, uma questão de julgamento pessoal e reflexo das preferências individuais. Não obstante, pesquisas demonstram 
uma certa uniformidade entre os consumidores na classificação dada aos produtos com base na estética;

- qualidade percebida: utiliza-se de medidas indiretas como base de comparação entre marcas. Junto com a dimensão anterior; parecem ser as que mais se aproximam dos conceitos colocados por Engel, Blackwell e Miniard" para "dimensōes de necessidades" e de "conjunto de consciência" ${ }^{10}$. As imagens, propaganda e os nomes de marcas - percepçāo da Qualidade, mas não a própria Qualidade - podem ser críticas. Esses autores comentam pesquisas recentes, nas quais foi verificado que o país onde um produto é produzido, muitas vezes é considerado pelos consumidores como um sinal de sua Qualidade. Por esta razāo, algumas empresas de origem japonesa com fábricas nos EUA, têm sido cautelosas na divulgaçāo da origem dos produtos ("made in USA"). Percebe-se que a reputaçāo é, de fato, um dos principais fatores que contribuem para formação da Qualidade Percebida, portanto, aumentando a percepção da imagem e a probabilidade de inserçāo no conjunto de consciência.

Como estamos falando do relacionamento entre necessidades do consumidor e estratégias de operaçōes, devemos estar atentos para o fato de que nem todas as dimensōes da qualidade aqui colocadas se referem ou sāo passíveis de ações na esfera da funçāo de manufatura (ver figura 2 ).

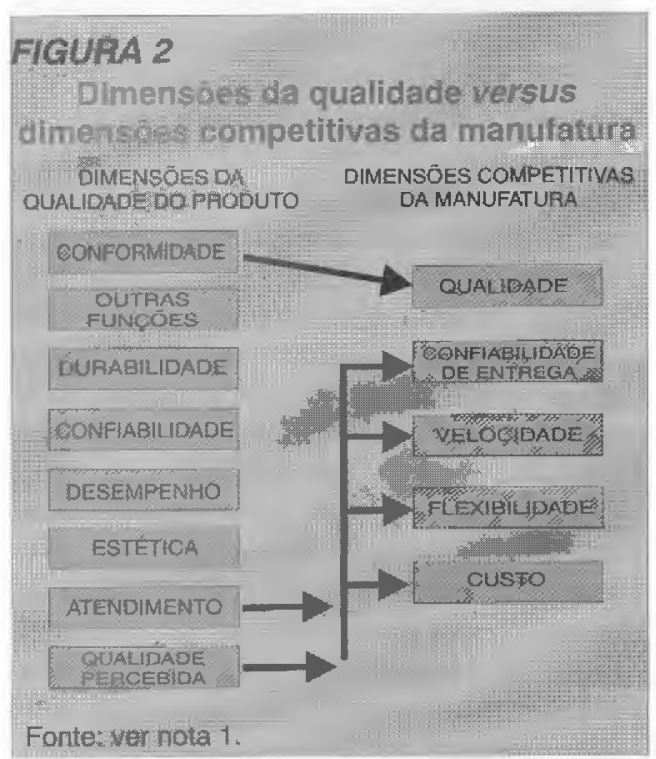

Assim, devem ser considerados aspectos multifuncionais, quando se examinam as açōes necessárias ao atendimento pleno dos requisitos dos consumidores, sob a ótica das dimensóes da qualidade propostas por Garvin ${ }^{11}$.

\section{AS DIMENSÕES DE NECESSIDADES DO CONSUMIDOR}

Segundo Engel, Blackwell e Miniard ${ }^{12}$, a probabilidade de manutenção do status quo de um estado presente está relacionada à maneira como evolui a percepção que o consumidor tem desse estado, no sentido de saber se suas necessidades de consumo estāo sendo atendidas sa-

tisfatoriamente.

Para que ocorra o reconhecimento de uma necessidade de mudar o estado, é preciso que, de alguma forma, seja enviado um estímulo ao consumidor, trazendo à sua consciência (ou a um plano de interesse de maior prioridade) a necessidade latente dentro de si. Nada mais é, como dizem os autores, do que a percepção da diferença entre o estado desejado de alguma coisa e a situação atual, su-

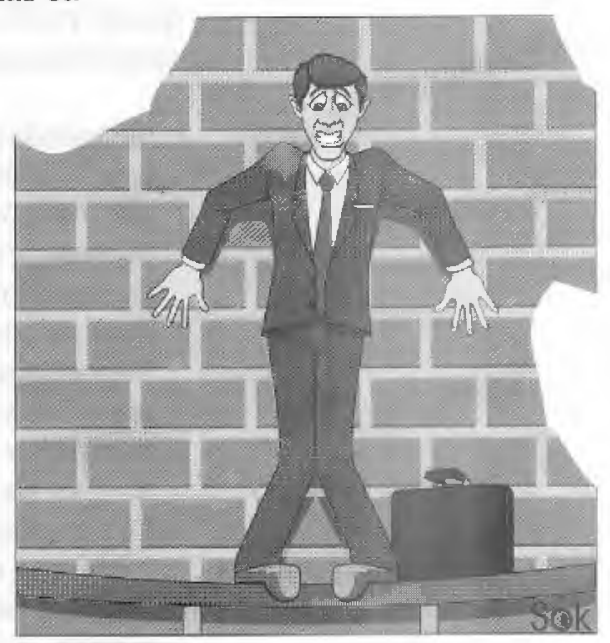
ficiente para despertar e ativar o processo decisório.

Utilizando aqui as dimensões de necessidades colocadas por Engel, Blackwell e Miniard $^{13}$, podemos fazer uma espécie de "referência cruzada", ou seja, considerar como determinado produto, que tem um certo "perfil" em termos de dimensões de qualidade, comporta-se em determinado contexto, considerando ainda um segmento de mercado caracterizado por clientes que têm também um certo perfil próprio de necessidades.

O que estamos tentando dizer é que um consumidor com um certo perfil próprio de necessidades pessoais, para atender a determinadas exigências ditadas pelo contexto em que vive, irá exigir produtos ou serviços (meios, enfim) que possuam também certo perfil próprio de características que lhe pareçam harmônicas ou que sejam percebidas como tal.

São apresentadas e conceituadas, a seguir, nove dimensões de necessidades, as
9. ENGEL, J. F., BLACKWELL R.D., MINIARD, P.W. Op. cit.

10. Ver As dimensōes de necessidades do consumidor e Qualificadores e ganhadores de pedidos, neste artigo.

11. GARVIN, D. A. Op. cit.

12. ENGEL, J. F., BLACKWELL, R.D, MINIARD, P.W. Op. cit.

13. Idem, ibidem. 


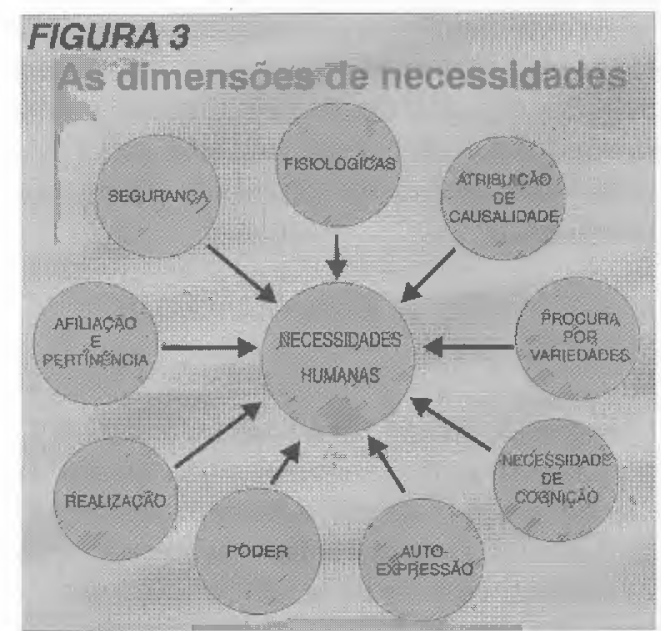

quais podem ser isoladas e explicadas empiricamente (ver figura 3 ).

- necessidades fisiológicas: segundo Maslow ${ }^{14}$, as necessidades fisiológicas devem ser atendidas antes das outras. Tais necessidades eliminam e recebem prioridade maior no processamento de informaçōes na mente do consumidor;

- segurança: cuidado com a segurança é algumas vezes de vital importância para basear ou dar peso e consistência à formaçāo da imagem de algum produto. Por exemplo, carros com air-bag;

- afiliação e pertinência: sendo uma dimensão raramente satisfeita em sua plenitude, sua importância corresponde ao amor e aceitação, ou do desejo de "parte do grupo". A psicologia moderna tem demonstrado a necessidade que o ser humano tem de viver e se relacionar em grupos sociais;

- realização: tem grande impacto e é uma motivação básica e universal, embora possa ser expressa de várias maneiras diferentes de uma cultura para outra. É evidente que produtos e serviços que permitam atingir metas de vida, possuem uma excelente chance de sucesso, como, por exemplo, o cartão de crédito, que pode trazer sensação de realização;

- poder: estimula as pessoas a procurarem soluções para problemas, enfatizando as alternativas que tenham ou ofereçam real impacto no ganho de controle. Algumas pessoas podem ser motivadas fortemente pela dimensão da realização, mas ser condescendentes com relação ao poder; 14. MASLOW, A.H. Motivation. Harper\&Row, 1970.

15. ENGEL, J. F., BLACKWELL, R. D., MINIARD, P. W. Op. cit. te $e^{\prime \prime}$. Por exemplo, uma propaganda do tipo "Nosso hotel espera por aqueles que sabem o que quer";

- necessidade de cognição (conhecimento): embora de modo geral possamos dizer que, de alguma maneira, todas as pessoas pensam, existem diferenças na intensidade, maior ou menor, com que os indivíduos exibem um desejo de conhecer, entender, sistematizar e priorizar. As pessoas com elevada necessidade de cogniçāo săo mais sujeitas à influência da qualidade dos argumentos usados em anúncios do que as outras. Suas atitudes, uma vez tomadas, sāo as mais persistentes ao longo do tempo;

- procura por variedades: é mais comum quando existem muitas alternativas similares, baixo envolvimento e elevada freqüência de compras. Engel, Blackwell e Miniard ${ }^{15}$ afirmam que todos necessitam de um certo grau de estímulo, e que, quando o nível ótimo de estímulo é alcançado, é disparado um comportamento exploratório (busca). Muitas pessoas parecem ser "buscadoras de sensações", aparentemente motivadas pela necessidade de um elevado e contínuo nível de estímulo, desdenhando tudo aquilo que possa sugerir enfado. Os "buscadores de sensaçōes" tendem a ser os primeiros a adotar o "novo" e a moda. Existem boas razōes para se crer que tanto o enfado como a busca de sensaçōes sejam explicações plausíveis para ocorrências de mudanças de marcas. Isto significa dizer que tais mudanças podem ocorrer por razões outras que não a insatisfação com relaçāo às escolhas e preferências atuais. É provável que o uso repetido de uma marca venha a causar um efeito de saciedade e diminua sua percepção de utilidade;

- atribuição de causalidade: esta dimensão trabalha com a existência ou não de motivaçāo para verificar se a influência causal de uma dada situaçāo é resultante de fatores internos a um dado objeto ou se pode ser atribuída a algum fator externo. Normalmente, nos casos de alto envolvimento consumidor-produto, quanto mais elevado for o conhecimento e a necessidade de cogniçăo do consumidor, maior será a probabilidade de que ele tenha grande motivação para pesquisa da causalidade. Relacionando estes conceitos ao próximo item deste artigo, referente aos fatores qualificadores, 
podemos concluir que as dimensões de necessidades apresentadas estão situadas na "raiz" das coisas, não estando apenas restritas ao processo de definição dos fatores qualificadores como principalmente na configuração do próprio perfil de envolvimento e, finalmente, na definição do contexto representado pelos pressupostos de pesquisa (ver figura 4), ou seja, as diretrizes nas quais o consumidor irá se basear para nortear o seu processo de busca.

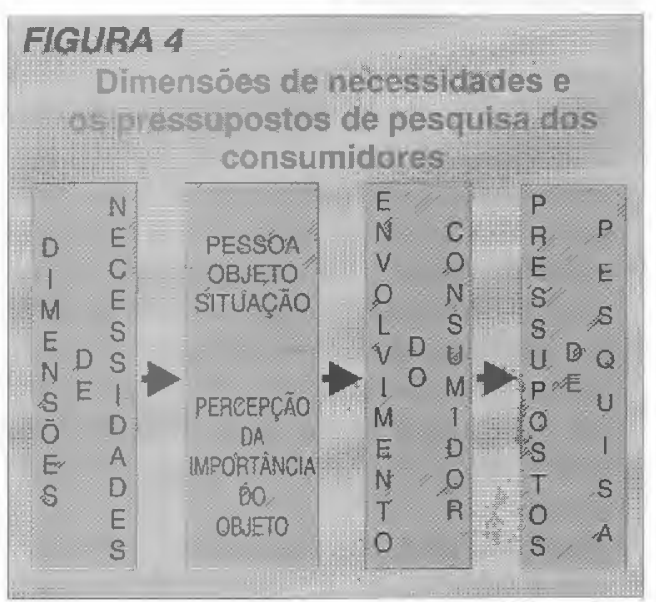

\section{QUALIFICADORES E GANHADORES DE PEDIDOS}

Antes de mais nada, é importante uma reflexão acerca do que realmente faz com que determinado cliente prefira uma marca, uma loja, ou escolha determinado candidato em vez de outros (até com maiores vantagens comparativas aparentes). Para tanto, como se trata de aspectos em sua maioria subjetivos, seria necessário encontrar um arcabouço analítico, racional e objetivo o suficiente para permitir uma visão estruturada do assunto.

Hill e Slack ${ }^{16}$ apresentam os conceitos de fatores "qualificadores" $\mathrm{e}$ "ganhadores" de pedidos como uma tentativa de estruturar e direcionar, de forma priorizada, as açōes de manufatura, de modo a perseguir objetivos que redundem em efetivo ganho de competitividade de mercado.

Partindo desses conceitos, os autores distinguem entre objetivos "ganhadores de pedidos" e objetivos "qualificadores".

Os objetivos ganhadores de pedidos são aqueles que, direta e significativamente, contribuem para o ganho de negócios. São vistos pelos consumidores como sendo os fatores-chave da competitividade, sendo os que mais influenciam suas decisões sobre o nível de negócios a ser mantido com a empresa. Desse modo, ser melhor do que a concorrência, e ter melhor desempenho nesses fatores, significa mais negócios e é, muitas vezes, o determinante entre a vitória e a derrota.

Os objetivos qualificadores podem ou não ser os determinantes do sucesso competitivo, mas representam os aspectos da competitividade nos quais o desempenho das operaçōes devem estar acima de determinado nível, para que a empresa, ou produto, seja considerada pelos consumidores como possível fornecedora. Portanto, abaixo desse nível a empresa nem entra na concorrência e, do mesmo modo, acima dele será considerada.

É interessante notar a semelhança com os conceitos colocados por Engel, Blackwell e Miruard ${ }^{17}$, com relação às análises "de consciência" e "de imagem", A análise de consciência tem por objetivo avaliar a consciência de marca que os consumidores possuem, ou seja, em que medida estes se lembram de marcas de determinado produto, isto é, qual é o correspondente conjunto de "consciência".

Fazendo um contraponto com Hill, Slack, Garvin, e Gianesi e Corrêa ${ }^{18}$, podemos notar claramente uma semelhança de conceitos entre a dimensão de "qualidade percebida", os fatores qualificadores e o que Engel, Blackwell e Miniard ${ }^{19}$ chamam de "conjunto de consciência" (ver figura 5).

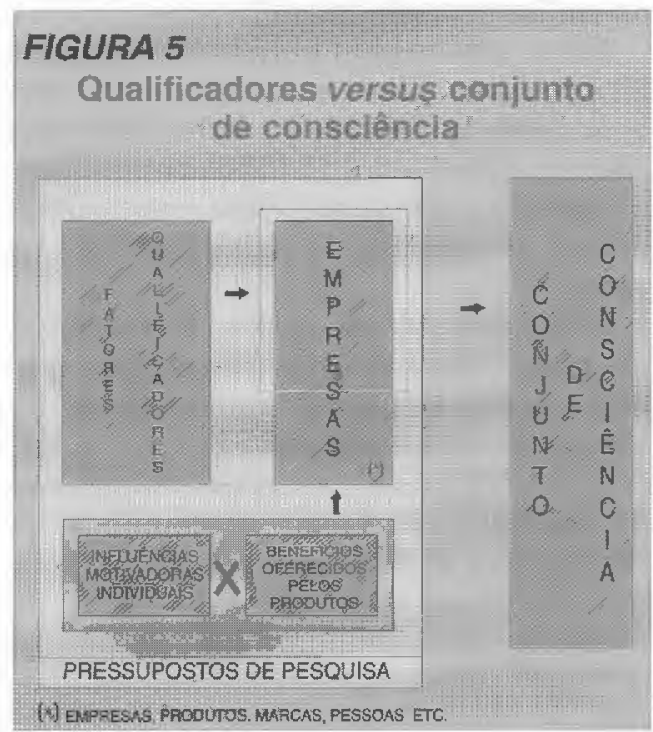

16. HILL, T. Op cit: SLACK, N. Op. cit.

17. ENGEL, J. F, BLACKWELL, R.D., MINIARD, P.W. Op. cit

18. HILL, T. Op. cit., SLACK, N. Op. cit., GARVIN, D. A. Op cit., GIANESI, I. G. N., CORREA, H. L. Op. cit.

19. ENGEL, ป. F., BLACKWELL, R.D., MINIARD, P.W. Op. cit. 


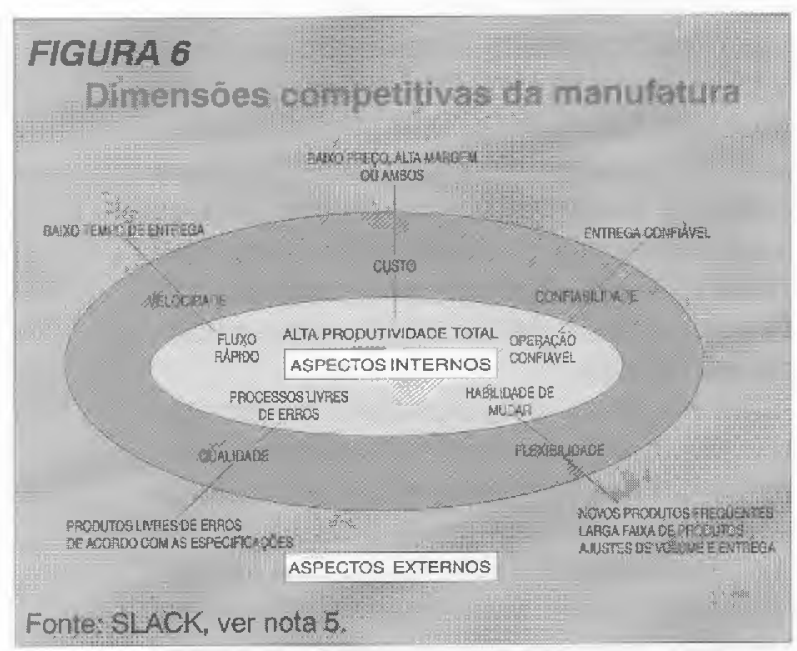

Os fatores qualificadores de mercado normalmente definem um elenco de empresas "válido" para o consumidor. O balanço entre as influências individuais (tais como experiências passadas e motivadores de busca) e os objetivos oferecidos pelos produtos restringem ainda mais esse elenco. No entanto, é a satisfação sentida pelo consumidor que irá determinar a inserção ou năo, de uma dada empresa em seu conjunto de "consciência". Conhecendo o conjunto de "consciência" correspondente a determinado produto, um objetivo de marketing poderia ser, portanto, situar determinada marca dentro deste conjunto.

Para a análise de imagem, a investigação é voltada mais para identificar, para cada marca dentro do conjunto de consciência, o conjunto de associaçôes que existem entre essas e outras partes de informaçóes que estão armazenadas na memória. O conjunto inteiro de associaçôes denomina-se "imagem da marca".

Essas associações podem envolver as propriedades físicas e atributos da marca bem como benefícios e sentimentos que afloram quando do consumo do produto, símbolos e pessoas que estão associados à marca, campanhas de publicidade e slogans.

O objetivo de uma análise de imagem é identificar as associações específicas que definem uma imagem da marca, bem como a força de tais associações.

\section{AS DIMENSÕES DE COMPETITIVIDADE DE PRODUTOS E SERVIÇOS}

\section{Manufatura}

Slack $^{20}$ apresenta estudos que relacio- tindo do mercado ou arena concorrencial onde são colocados os produtos, ainda sob a ótica da obtenção de um quadro estruturado sistemicamente, que permita uma análise competitiva dos aspectos de manufatura. Fazendo isso, esse autor pretende também trazer a visão dos clientes e do mercado em geral para dentro da empresa e tirar daí os itens a serem contemplados prioritariamente pelas estratégias de manufatura.

Esse autor coloca estas dimensóes de competitividade da manufatura, tal como ilustrado na figura 6.

- qualidade: fazer certo, ou seja, produtos sem erros, de acordo com as especificaçōes do projeto;

- velocidade: fazer rápido, podendo entregar mais rápido do que os concorrentes;

- confiabilidade de entrega: manter os prazos prometidos, o que requer aptidão para estimar datas de entrega, ter clareza na comunicação das datas aos clientes e ter capacidade efetiva para fazer com que as entregas ocorram pontualmente;

- flexibilidade: ter capacidade para variar e adaptar as operações, de modo a considerar alteraçōes nas necessidades dos clientes e mudanças nos processos de produção, bem como capacidade para fazê-lo cum rapidez suficiente (timing);

- custo: ter habilidade para produzir a custos mais baixos do que os concorrentes, o que, a longo prazo, implica obter recursos mais baratos e ser mais eficiente que a concorrência para transformá-los em produtos finais.

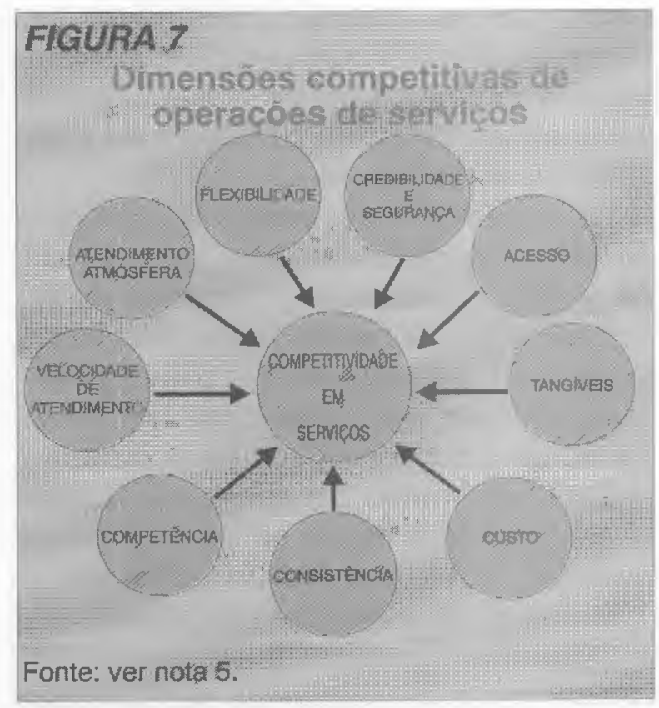




\section{Serviços}

Do mesmo modo, Gianesi e Corrêa ${ }^{21}$ colocam as dimensōes de competitividade das operaçōes de serviços (ver figura 7) como resultante da ponderação dos fatores que influenciam a formaçăo das expectativas dos clientes e dos fatores que influenciam a percepçāo do serviço prestado, tal como descrito a seguir.

- atendimento/atmosfera: atençāo personalizada ao cliente, boa comunicação, cortesia, ambiente;

- consistência: conformidade com experiência anterior, ou seja, ausência de variabilidade no resultado ou processo;

- competência: habilidade e conhecimento para executar o serviço. Relaciona-se com as necessidades "técnicas" dos consumidores;

- velocidade de atendimento: prontidão da empresa e seus funcionários em prestar o serviço. Relaciona-se com o tempo de espera (real ou percebido);

- flexibilidade: capacidade de mudar e adaptar a operação, devido a mudanças nas necessidades dos clientes, no processo ou no suprimento de recursos;

- credibilidade/segurança: baixa percepção de risco, corresponde à habilidade de transmitir confiança;

- acesso: facilidade de contato e acesso, localizaçăo conveniente, horas de operação;

- tangíveis: qualidade e/ou aparência de qualquer evidência física (bens facilitadores, equipamentos, instalaçōes, pessoal, outros consumidores);

- custo: fornecer serviços de baixo custo.

\section{FORMAÇ̃O DAS ESTRATÉGIAS DO SISTEMA DE OPERAÇÕES}

Antes de começarmos a pensar em estratégias do sistema de operações, é necessário observar que o processo de formação do conjunto de "consciência" (conforme figura 5) será mais abrangente e terá maior profundidade analítica à medida que o envolvimento do consumidor também for elevado (ver figura 8 ).

Podemos conceituar a profundidade analítica como sendo o nível de detalhe em que ocorrerá a análise e avaliação das opçōes oferecidas pelas empresas do "conjunto de consciência".

Desse modo, podemos afirmar que:

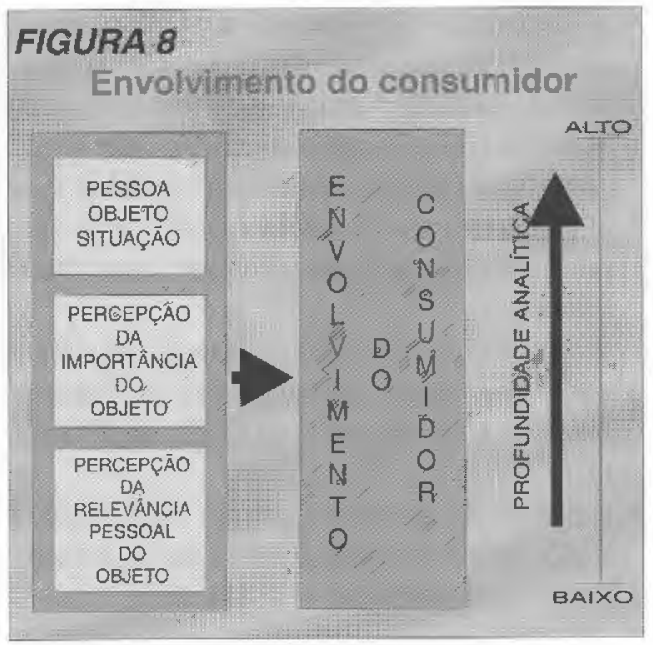

- o envolvimento é uma função da pessoa, objeto (produto/serviço) e situaçăo;

- o ponto de partida é sempre a pessoa, englobando motivaçóes na forma de necessidades e valores, os quais, por sua vez, são uma reflexăo do autoconceito;

- o envolvimento é ativado quando o objeto é percebido como sendo um instrumento para o alcance de importantes necessidades, metas e valores;

- o envolvimento, portanto, é uma reflexão de forte motivação, na forma de uma alta relevância pessoal percebida de um produto ou serviço em um contexto particular.

Conseqüentemente, fica claro o processo de formação dos pressupostos de pesquisa (ver figura 9) que irão nortear:

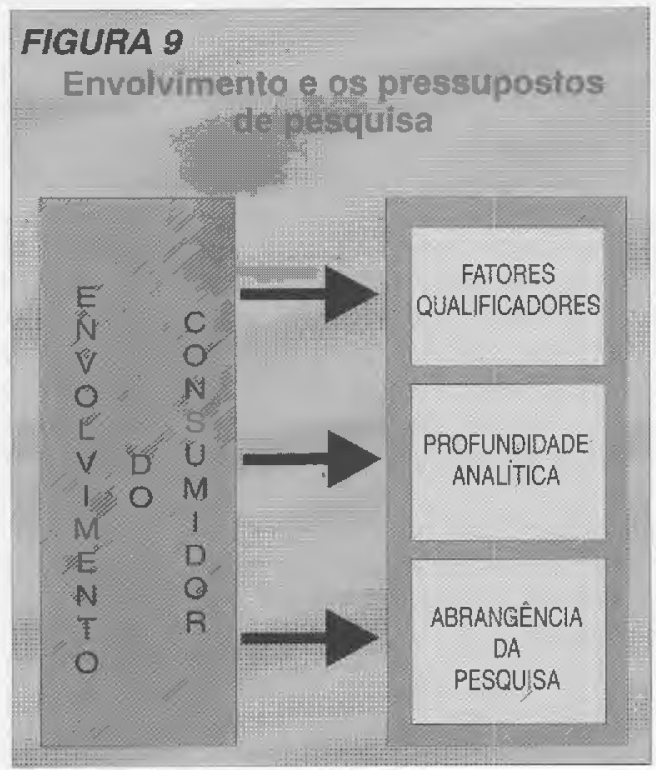

21. GIANESI, I. G. N., CORRÊA, H. L. Op. cit. 


\begin{abstract}
ARTIGOS
22. SLACK, N. Op. cit.

23. HILL, T. Op. Cit., SLACK, N

Op. cit., GIANESI, I. G. N.

CORREA, H. L. Op. cit.

a definição dos fatores qualificadores, ou seja, os requisitos que produtos (serviços, marcas, empresas etc.) devem atender para se considerarem "no jogo" concorrencial (Entendendo, também, que o conceito de fatores qualificadores, como diz Slack ${ }^{22}$, é essencialmente dinâmico.);

a definição da profundidade analítica com que serão observados os fatores qualificadores por parte do consumidor;

a definição da abrangência da pesquisa e do "conjunto de consciência admissível" por parte do consumidor.

Independente de ser manufatura ou serviços, a análise a ser feita refere-se a como traduzir os pressupostos de pesquisa definidos, em aspectos que devam ser considerados para formação das estratégias do sistema de operaçóes (ver figura 10).

Os fatores qualificadores podem fornecer uma visão bastante pragmática e concreta a respeito "do que fazer" para se situar "no jogo".
\end{abstract}

Em resumo, como corolário do presente trabalho, a grande questão que procuramos tratar refere-se a como obter uma visão analítica estruturada que permita, mediante um processo claramente definido e passível de entendimento, chegar às estratégias de manufatura (ou serviços) mais adequadas, tendo em vista os pressupostos básicos de pesquisa típicos dos consumidores de determinado segmento-alvo.

Ficou claro que, respondendo a essa questão, estaremos respondendo também à definição das necessidades de competitividade do negócio como um todo.

Hill, Slack, Gianesi e Corrêa ${ }^{23}$ apresentam uma visão claramente voltada às necessidades tipicas de atividades de manufatura e serviços, procurando enxergar as características de mercado externo como oportunidades para desenvolvimento interno da capacidade competitiva do sistema de operaçōes de uma empresa.

As observaçōes finais que registramos aqui referem-se ao vasto campo adicional

\title{
UM EXEMPLO DE APLICAB̧̄̃O
}

Suponhamos um segmento de mercado composto por consumidores que desejam fazer uso regular de um micro notebook, para colocaçăo de pedidos de compra à matriz, via modem.

Em primeiro lugar, considerando as dimensōes de competitividade para esse tipo de produto e, ainda, também seu uso projetado, o que vai qualificar um dado fabricante será:

qualidade ${ }^{1}$ : o produto deve fazer exatamente aquilo que se espera que faça. Desse modo, é necessário que o sistema de manufatura tenha consistência suficiente na obtençáo das características do produto (processo estável);

velocidade: o produto deve estar disponivel rapidamente para entrega (este tempo é uma variável relevante no contexto concorrencial). Isso significa que o sistema tem duas opções:

* trabalhar com estoque de produtos acabados: uma vez colocado o pedido, o problema maior reside na velo. cidade com que o sistema de entrega consegue colocar o produto nas mãos do consumidor;
* trabalhar sem estoque de produtos acabados: uma vez colocado o pedido, o problema reside na velocidade com que o sistema consegue produzir o produto e o de entrega, fazê-lo chegar às mãos do consumidor;

confiabilidade de entrega: por haver um custo de oportunidade (custo de perda de vendas) considerado significativo pelo consumidor típico deste segmento, o produto deve ser entregue na data efetivamente negociada. Para tanto, o sis tema de manufatura e entrega deve ter consistência suficiente nos tempos de processo, de tal modo a resultar nas menores variações possíveis;

flexibilidade: nesse caso específico, considerando o nosso exemplo, como se trata de um produto relativamente padronizado no mercado, este fator não apresenta grandes implicaçōes estratégicas;

custo: o produto deve ter um preço compatível com o praticado pela concorrência. A empresa deve ser capaz de produzir a custos mais baixos, o que significa maior eficiência nas compras dos insumos e nos processos de transformação.

Em segundo lugar, a profundidade analítica dos consumi- 


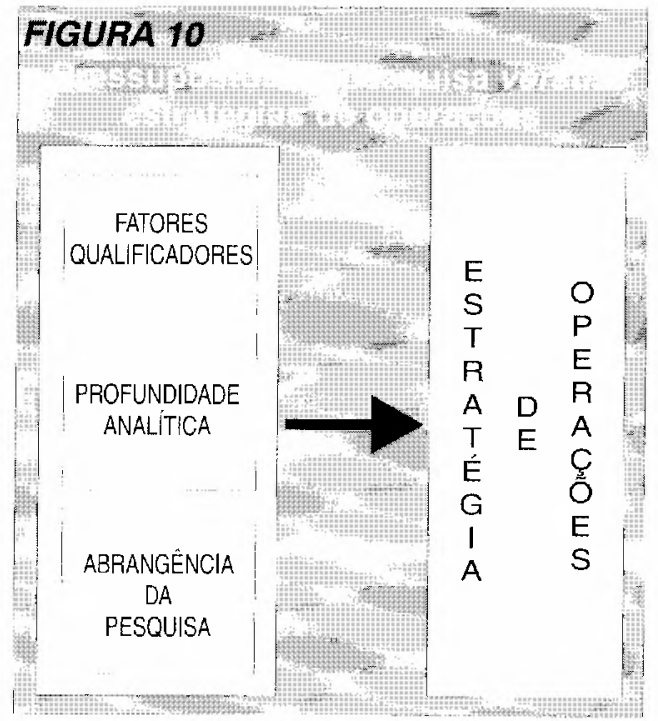

que se abre para futuras pesquisas, sobre como fazer uma análise cruzada desses fatores com as dimensões de necessidade colocadas por Engel, Blackwell e Miniard ${ }^{24}$, de forma a privilegiar uma visão que correlacione os aspectos puramente de marketing com aqueles típicos da necessi- dade de adotar estratégias de manufatura, que visem a aumentar a competitividade do negócio como um todo. É importante enfatizar a afirmação desses últimos autores, de que "una compra nunca ocorrerá, a menos que as necessidades (ou motious) essenciais sejam ativados ou satisfeitos".

A pesar de reconhecer a importância de se considerar as dimensoes de conhecimento utilizadas por esses autores para estruturar a mémória do consumidor, é importante colocar a idêntica importância da correta consideração dessas percepçōes, quando da elaboração da estratégia de operaçóes de um dado negócio.

Como podemos observar, nas afirmaçōes e estudos de Hill, Slack, Gianesi e Gianesi ${ }^{25}$ existem cvidentes correlações entre os aspectos por eles contemplados e as dimensöes de conhecimento.

Cada decisāo tomada no âmbito do sistema de operaçoes de uma empresa pode afetar as dimensões de conhecimento do produto, da compra e do uso, a que permite identificar aí mais um vasto campo para futuras pesquisas e estudos.
24. ENGEL, J. F., BLACKWELL R.D., MINIARD, P.W. Op. cit

25. HILL, T. Op. cit., SLACK, N Op. cit., GIANESI, I. G. N. CORRËA, H. L. Op. cit dores, devido ao seu alto envolvimento com o produto, além de sua situação específica de uso, deverá ser de moderada para alta. Isso significa a necessidade de um rigor maior na obtenção consistente das características qualificadoras descritas acima.

Por último, a abrangência da pesquisa também deverá, pelo mesmo motivo apresentado, contemplar uma quantidade moderada de opçóes disponiveis no mercado.

Desse modo, a empresa ou seu produto deverá apresentar alguma característica que o destaque dos demais, para aumentar a probabilidade de se fixar como opção constante do "conjunto de consciência" do consumidor.

O quadro 1 resume o que foi apresentado para este exemplo.

1. Ver As múltiplas dimensōes da Qualidade, neste artigo.

\section{5}

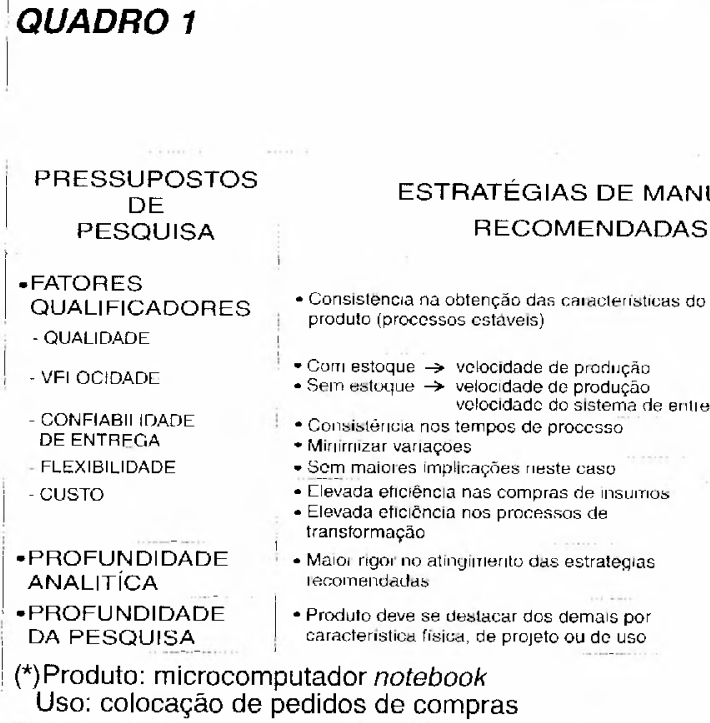

